Review

\title{
Soybean Oil Fat Emulsion to Prevent TPN-Induced Liver Damage: Possible Molecular Mechanisms and Clinical Implications
}

\author{
Masuhiro Nishimura, ${ }^{*, a}$ Mari Yamaguchi, ${ }^{a}$ Shinsaku Naito, ${ }^{a}$ and Aiko Yamauchi ${ }^{b}$ \\ ${ }^{a}$ Division of Pharmacology, Drug Safety and Metabolism, Otsuka Pharmaceutical Factory, Inc.; 115 Tateiwa, \\ Muya-cho, Naruto, Tokushima 772-8601, Japan: and ${ }^{b}$ Department of Pharmaceutical Information Science, \\ Graduate School of Pharmaceutical Science, The University of Tokushima; 1-78 Sho-machi, \\ Tokushima 770-8505, Japan. \\ Received February 3, 2006
}

\begin{abstract}
Long-term total parenteral nutrition (TPN) is known to be associated with cholestasis and hepatic steatosis, which can be lethal in infants who cannot be fed orally. The present review focuses on the metabolic complications in the liver that may occur due to the excessive administration of fat-free TPN. We have recently developed an infant rat model of hepatic dysfunction and steatosis induced by overdose of fat-free TPN. In this model, plasma levels of liver enzymes in the fat-free TPN group were found to be significantly higher than in the other groups (i.e., the oral diet and fat-containing TPN groups). Pathological examination showed hepatomegaly and severe fatty changes without cholestasis in the liver of infant rats that received fat-free TPN. We clearly demonstrated that the addition of soybean oil emulsion to the TPN regimen prevented hepatic dysfunction and fatty changes. In the present review, we discuss the molecular mechanism of the hepatic dysfunction induced by fatfree TPN and the role of soybean oil fat emulsion in the TPN regimen. We also discuss the clinical implications of soybean oil-containing TPN solutions and point out the importance of including fat in the TPN regimen in order to prevent the hepatic abnormalities associated with the excessive administration of fat-free TPN.
\end{abstract}

Key words total parenteral nutrition; soybean oil emulsion; hepatic steatosis; cholestasis; mRNA; xenobiotic transporter

\section{INTRODUCTION}

Total parenteral nutrition (TPN), which is recognized as one method for parenteral hyperalimentation, has been found to be an effective and relatively safe method for supplying energy and nutrients to surgical patients. Following improvements in parenteral regimens including vitamins and trace elements and in catheter techniques to reduce the septic complications associated with TPN, TPN has been widely employed to provide complete nutritional support and therapeutic benefits in a variety of pathophysiological settings in which patients are unable to eat. However, TPN-induced hepatobiliary dysfunction, which was first described by Peden et al. ${ }^{1)}$ has been recognized as a cause of severe morbidity and a life-threatening complication of TPN, especially in neonates and infants. Hepatic dysfunction with steatosis is the most common complication associated with fat-free TPN in adults, and cholestasis is more common in infants. ${ }^{2,3)} \mathrm{Re}$ cently, the 3-component infusion solution containing amino acids, glucose, and soybean oil emulsion, GA-1080 (MIXID ${ }^{\circledR}$, Otsuka Pharmaceutical Factory, Inc.; Tokushima, Japan), has been demonstrated to be effective in overcoming such hepatic morbidity in clinical studies. ${ }^{4)}$ Intravenous fat emulsions, especially soybean oil, are now available as a source of essential fatty acids in patients receiving TPN, and the "three-in-one" solution GA-1080 has been found to be clinically safe, stable, and economical. However, the multifactorial pathogenesis of TPN-induced hepatic dysfunction remains unclear, and the molecular mechanisms by which GA-1080 prevents hepatic dysfunction have not yet been identified.

We have recently developed an infant rat model of hepatobiliary dysfunction. ${ }^{5}$ ) Using this animal model, we have clearly demonstrated the metabolic complications in the liver that may occur due to the excessive administration of fat-free TPN in infant rats. Furthermore, we have shown that includ- ing fat in the TPN regimen is very important in preventing TPN-induced hepatic dysfunction. In this review, we describe the molecular mechanisms and the clinical implications of soybean oil in TPN solutions in avoiding the hepatic complications associated with parenteral nutrition.

\section{INFANT RAT TPN MODEL WITH HEPATOBILIARY DYSFUNCTION}

Since the first studies of TPN in animal models conducted in 1968 by Dudrick et al., ${ }^{6}$ ) it has been known that only a limited number of species (such as the dog, cat, rabbit, and guinea pig) can tolerate the surgical procedures required for TPN, and few studies have employed rats as an animal model for TPN. In 1981, Tashiro and Meng ${ }^{7)}$ were the first to report a technique for long-term TPN in unrestrained weanling or infant (3-week-old) rats, thus establishing an animal model for pediatric TPN. Numerous studies have focused on the optimal TPN composition in mature rats, but few have addressed this issue in infant rats.

We have recently developed an infant rat model with hepatic dysfunction and steatosis induced by overdose of fatfree TPN. ${ }^{5)}$ After 30 infant (3-week-old) male Sprague-Dawley rats weighing $60-70 \mathrm{~g}$ were fasted overnight, a silastic catheter $(0.5-\mathrm{mm}$ ID) was implanted under general anesthesia with diethyl ether. The catheter was surgically inserted via the right jugular vein into the superior vena cava and was routed to the back of the neck to exit through a coil spring attached to a swivel, allowing free mobility of the animals within their individual metabolic cages. Infusion was started immediately after cannulation at $3 \mathrm{ml} / \mathrm{kg}$ body weight $/ \mathrm{h}$ for the first $12 \mathrm{~h}$ and then increased in a stepwise manner to 10 , 20 , and then $30 \mathrm{ml} / \mathrm{kg} / \mathrm{h}$ every $12 \mathrm{~h}$. On the third day, the dosage was increased to $40 \mathrm{ml} / \mathrm{kg} / \mathrm{h}$ (i.e., full-dose TPN) and maintained at that level thereafter. The total experimental pe- 


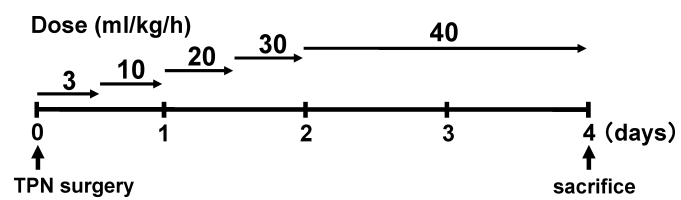

Fig. 1. TPN Regimen
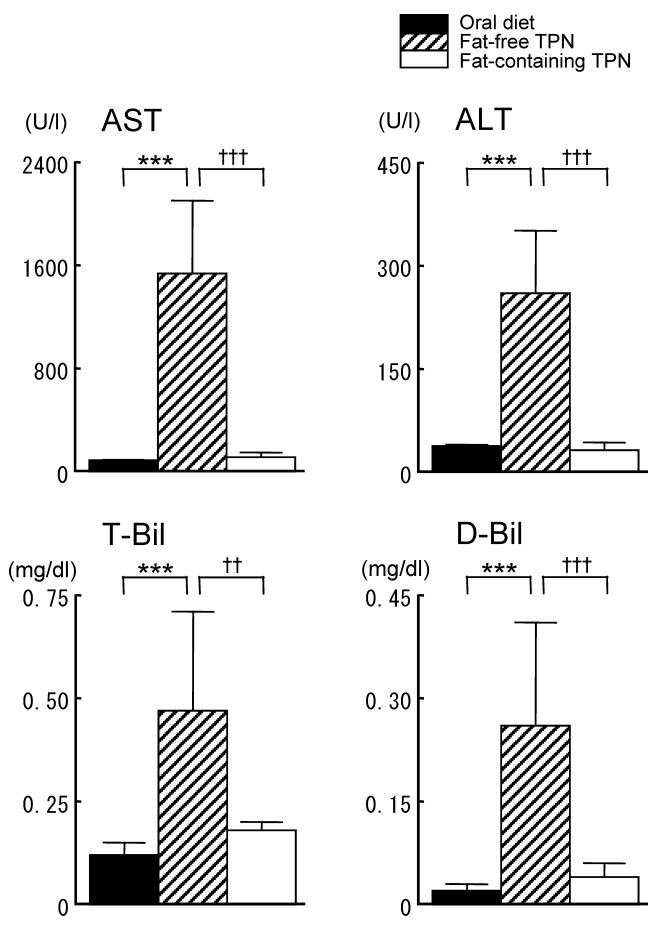

Fig. 2. Biochemical Examination (Serum AST, ALT, and Total and Direct Bilirubin) in Infant Rats That Received TPN for $4 \mathrm{~d}$

Values are mean \pm S.D. $(n=6-8)$. The statistical significance of differences between values was analyzed by Tukey's test. Significant difference at $* * * p<0.001 v s$. oral diet group, $\dagger^{\dagger} p<0.01$ and $\dagger \dagger p<0.001 v s$. fat-free TPN group. T-Bil: total bilirubin, D-Bil: direct bilirubin

riod was $4 \mathrm{~d}$, and continuous infusion was maintained (Fig. 1). In the serum biochemical analysis, aspartate aminotransferase (AST), alanine aminotransferase (ALT), total bilirubin (T-Bil), and direct bilirubin (D-Bil) levels were significantly higher in the group that received excessive administration of fat-free TPN than in the oral diet group ${ }^{5,8}$ (Fig. 2). In the morphological study, the livers of rats that received fat-free TPN were found to have large lipid droplets in all hepatocytes, which showed hypertrophy with eosinophilic granular cytoplasm. ${ }^{5,8)}$ Unicellular necrosis of some hepatocytes, unclear sinusoids, neutrophilic infiltration in Glisson's capsule, and enlarged Kupffer cells in the centrilobular region were also observed as hepatic morbidity. ${ }^{5)}$

TPN-induced hepatic dysfunction is generally said to express itself as fatty changes in the liver, but in infants, it is said to express itself as cholestasis. ${ }^{2,3,9-11)}$ The results of our study indicated that TPN-induced hepatic dysfunction is associated with biochemical, but not pathologically apparent, cholestasis in infant rats. This is in contrast to the findings in infant rabbits, which are the same as in human infants, in which TPN-induced hepatic dysfunction has been reported to be associated with cholestasis both biochemically and pathologically. ${ }^{12)}$ In rats, particularly in infant rats, there have so far been no reports in the literature indicating that TPN-in- duced hepatic dysfunction represents itself both biochemically and pathologically as cholestasis due to the peculiarities of rat physiology. Therefore, TPN-induced hepatic steatosis is thought to be due to hepatic immaturity only during infancy.

\section{ROLE OF SOYBEAN OIL FAT EMULSION IN THE PRE- VENTION OF TPN-INDUCED LIVER DAMAGE}

It should be noted that hepatic dysfunction is the most common complication associated with TPN. Several methods for preventing such hepatic dysfunction have been reported, such as the use of cyclic TPN ${ }^{13}$ ) or the administration of ursodeoxycholic acid, ${ }^{14)}$ metronidazole, ${ }^{15)}$ gentamicin, ${ }^{16)}$ antiTNF antibody, ${ }^{17)}$ cholecystokinin, ${ }^{18,19)}$ glutamine, ${ }^{20-23)}$ or steroids and growth hormone. Nevertheless, the problem of hepatic dysfunction in patients receiving TPN has yet to be completely overcome, and the mechanism of TPN-induced hepatic steatosis remains unclear.

Our experimental model was developed primarily to compare the hepatic changes observed in fat-free and fat-containing TPN in infant rats. The levels of AST, ALT, T-Bil, and DBil were significantly higher in the fat-free TPN group than in either the fat-containing TPN or oral diet groups, indicating that the liver damage was associated with fat-free $\mathrm{TPN}^{5,8}$ ) (Fig. 2).

In general, the livers of the rats in the TPN groups showed fatty changes with lipid staining using oil red $\mathrm{O}$, although the livers of the rats in the oral diet group showed the accumulation of glycogen in hepatocytes, a rough endoplasmic reticulum (RER) with a clear layer structure, and a few small fat droplets. ${ }^{5)}$ In the fat-free TPN group, the livers were found to have large lipid droplets in all hepatocytes, which showed hypertrophy with eosinophilic granular cytoplasm. Unicellular necrosis of some hepatocytes, unclear sinusoids, neutrophilic infiltration in Glisson's capsule, and enlarged Kupffer cells in the centrilobular region were also observed ${ }^{5,8)}$ (Fig. 3). No differences were noted between the perilobular and centrilobular regions. All hepatocytes in the rats in the fat-free TPN group had large lipid droplets and showed an absence of glycogen, nuclear vacuoles, nucleolar enlargement, expansive round mitochondria, fragmentation of the RER, and a partial loss of biliary microvilli in, as well as dilatation of, the biliary canaliculi. When compared with the fat-free TPN group, the $20 \%$ fat-containing TPN group was found to have smaller lipid droplets in all hepatocytes in the perilobular region and smaller vacuoles in all hepatocytes in the centrilobular region (Fig. 3). The hepatocytes in rats in the fat-containing TPN group were found to have small lipid droplets and to show an accumulation of glycogen and an RER with a well maintained clear layer structure in enlarged Kupffer cells with numerous lysosomes including small lipid droplets. Those pathomorphological findings clearly demonstrated that the addition of soybean oil emulsion to the TPN regimen prevented hepatic dysfunction and fatty changes.

\section{MOLECULAR MECHANISM OF STEATOSIS INDUCED BY FAT-FREE TPN AND ROLE OF SOYBEAN OIL FAT EMULSION IN TPN REGIMEN}

In order to clarify the mechanism of the hepatic dysfunc- 

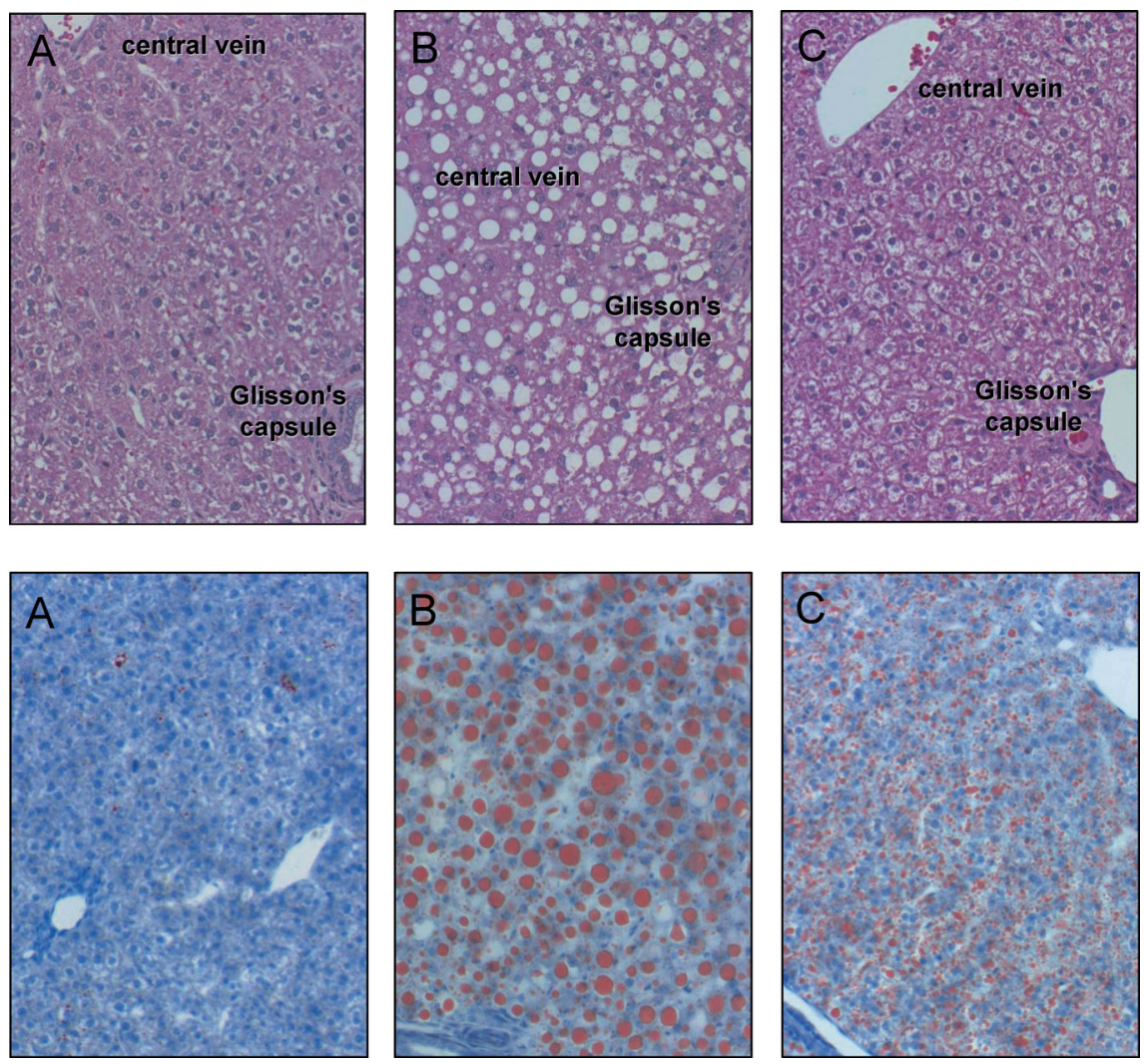

Fig. 3. Hepatic Changes in Infant Rats Receiving TPN with or without Fat

The upper and lower panels are H\&E staining and oil red O staining, respectively. A: oral diet group, B: fat-free TPN group, C: $20 \%$ fat-containing TPN group. (This photograph was originally presented in the Journal of Japanese Society for Parenteral and Enteral Nutrition Vol. 19, 2004 and presented here with its permission.)
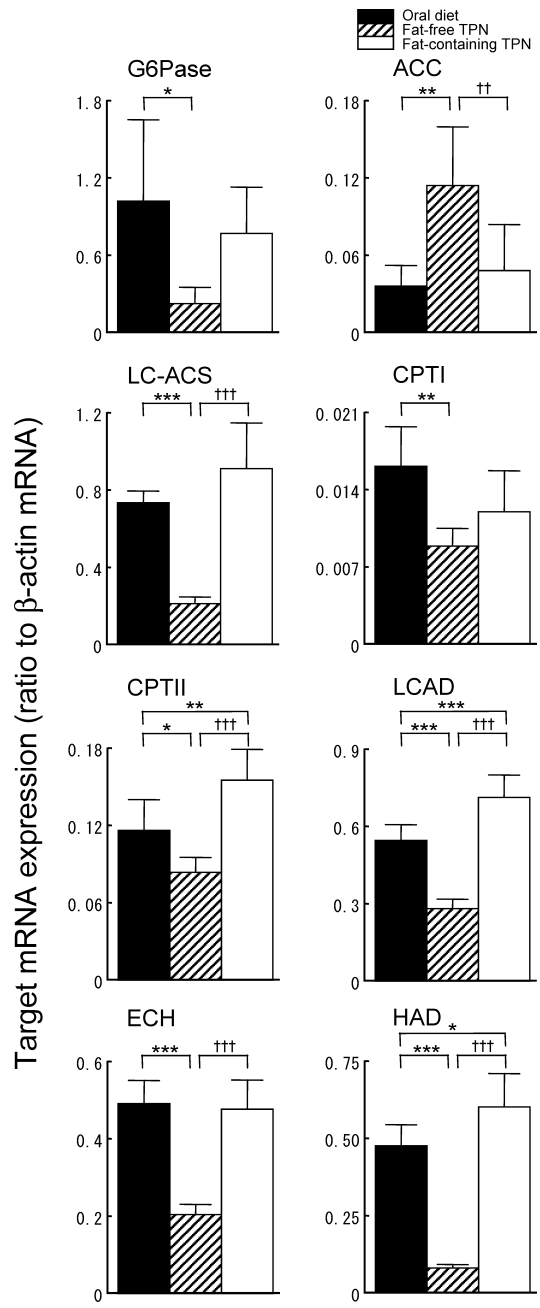
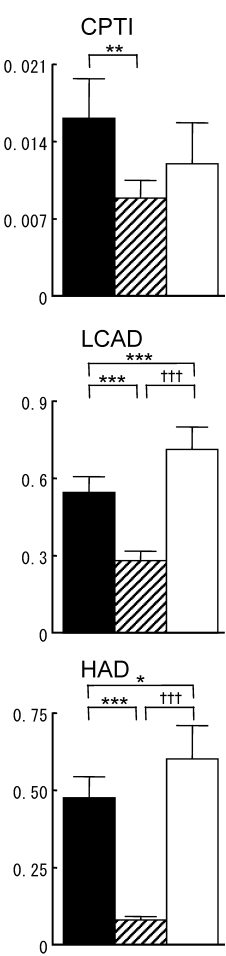

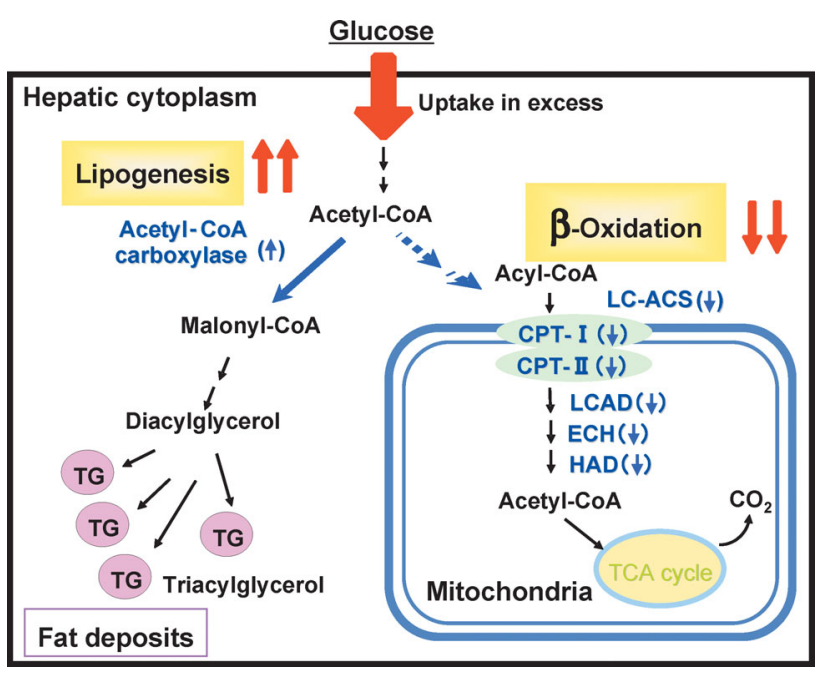

Fig. 5. Mechanism of Fat-Free TPN-Induced Hepatic Steatosis

LC-ACS: long-chain acyl-coenzyme A synthetase, CPTI: carnitine palmitoyltransferase I, CPTII: carnitine palmitoyltransferase II, LCAD: long-chain acyl-coenzyme A dehydrogenase, ECH: enoyl-coenzyme A hydratase, HAD: L-3-hydroxyacyl coenzyme A dehydrogenase.

Fig. 4. Changes in G6Pase, ACC, LC-ACS, CPTI, CPTII, LCAD, ECH, and HAD mRNA Expression in Infant Rats That Received TPN for $4 \mathrm{~d}$

Data are expressed as the ratio of the target mRNA to $\beta$-actin mRNA. Values are mean \pm S.D. $(n=6-8)$. The statistical significance of differences between values was analyzed by Tukey's test. Significant difference at $* p<0.05$, $* * p<0.01$, and $* * * p<0.001 v s$. oral diet group, $\dagger p<0.01$ and $\dagger \dagger p<0.001$ vs. fat-free TPN group. G6Pase: glucose-6-phosphatase, ACC: acetyl-coenzyme A carboxylase, LC-ACS: long-chain acyl-coenzyme A synthetase, CPTI: carnitine palmitoyltransferase I, CPTII: carnitine palmitoyltransferase II, LCAD: long-chain acyl-coenzyme A dehydrogenase, ECH: enoyl-coenzyme A hydratase, HAD: L-3-hydroxyacyl coenzyme A dehydrogenase. 
tion induced by fat-free TPN, we measured the hepatic mRNA levels of enzymes related to the metabolism of sugar and fatty acid using the high-sensitivity real-time RT-PCR method as described previously. ${ }^{24)}$ The mRNA expression of $\beta$-actin, a housekeeping gene, showed no up- or down-regulation following the administration of TPN regimens with or without fat. The mRNA level of glucose-6-phosphatase (G6Pase), which plays a pivotal role in gluconeogenesis, decreased following the administration of fat-free $\mathrm{TPN}^{8)}$ (Fig. 4), suggesting a decrease in the accumulation of sugar as glycogen in the liver. The mRNA levels of long-chain acyl-coenzyme A synthetase (LC-ACS), carnitine palmitoyltransferase I (CPTI), carnitine palmitoyltransferase II (CPTII), long-chain acyl-coenzyme A dehydrogenase (LCAD), enoylcoenzyme A hydratase (ECH), and L-3-hydroxyacyl coenzyme A dehydrogenase (HAD) decreased following the administration of fat-free TPN (unpublished observations) (Fig. 4). On the other hand, the mRNA level of acetyl-coenzyme A carboxylase (ACC), which plays a pivotal role in lipid synthesis, increased markedly following the administration of fat-free TPN (Fig. 4). These findings indicate that the infusion of excessive glucose without fat in TPN causes increased hepatic lipogenesis and decreased lipolysis and consequently leads to abnormally high triacylglycerol synthesis and its accumulation as lipid droplets in the liver, as shown in Fig. 5. When soybean oil fat emulsion was added to the TPN solution, the changes in these mRNA expression levels were smaller than those in the fat-free TPN group (Fig. 4). The inclusion of fat in the TPN regimen is therefore thought to be important for maintaining the metabolic homeostasis of the liver as far as possible.

\section{SOYBEAN OIL IN TPN REGIMEN PREVENTS HEPATIC CYTOCHROME P450 mRNA DOWN-REGULATION}

The hepatic cytochrome P450 (CYP) isoenzymes are involved in the detoxification of endogenous and exogenous compounds for further metabolism or elimination. Therapeutic drugs are mainly metabolized by the CYP1, CYP2, and CYP3 isoenzymes in the CYP families. ${ }^{25)}$ Notably, the CYP4 family has been shown to be related to the metabolism of fatty acids. ${ }^{26)}$ Changes in the CYP activities of patients receiving long-term TPN may affect the success of drug therapy or recovery from disease. Knodell et al. ${ }^{27)}$ reported that 7 -d parenteral infusion of a hyperalimentation solution containing glucose, amino acids, and electrolytes via the jugular vein led to a decrease in CYP-mediated oxidative metabolism in rats. Therefore, TPN therapy without fat may affect the pharmacokinetics of therapeutic drugs and eventually lead to adverse events in patients. Since the capacity of CYPmediated drug metabolism in the neonate or infant is lower than in the adult, ${ }^{28,29)}$ severe adverse reactions may occur in pediatric patients if additional pharmacotherapy is required during fat-free TPN therapy. It is therefore important to identify the specific changes in the hepatic CYP isoenzymes during fat-free TPN in the neonate or infant and to clarify the effects of including fat in the TPN regimen. However, to the best of our knowledge, there have been no reports in the literature focusing on the changes in hepatic CYP isoenzymes during TPN therapy. In this review, we therefore focus on demonstrating the changes in the mRNA expression of he-
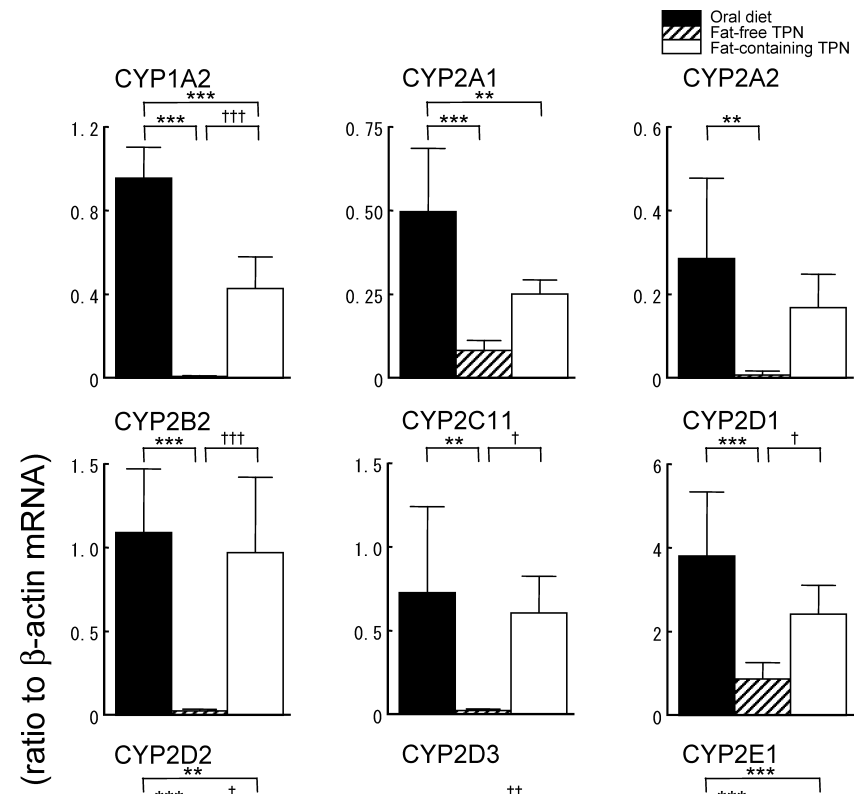

CYP2D3
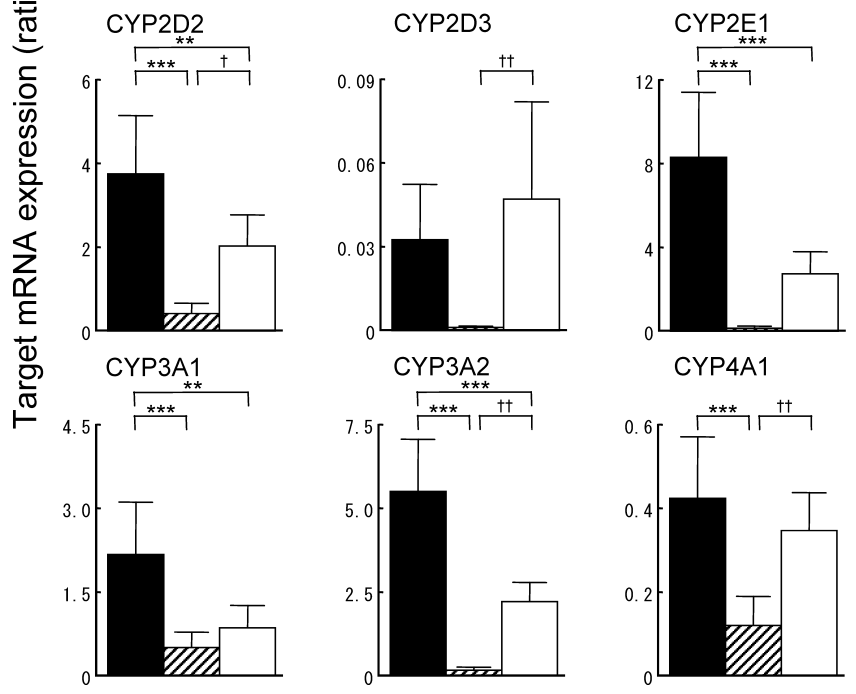

Fig. 6. Changes in CYP mRNA Expression in Infant Rats That Received TPN for $4 \mathrm{~d}$

Data are Expressed as the ratio of the target mRNA to $\beta$-actin mRNA. Values are mean \pm S.D. $(n=6-8)$. The statistical significance of differences between values was analyzed by Tukey's test. Significant difference at $* * p<0.01$ and $* * * p<0.001 v s$. oral diet group, $\dagger p<0.05$, $\dagger p<0.01$, and $\uparrow \dagger p<0.001 v s$. fat-free TPN group.

patic CYP isoenzymes in our infant rat model following the administration of TPN with or without soybean oil emulsion.

We demonstrated for the first time that the administration of TPN without fat induced marked and selective down-regulation of hepatic CYP mRNAs in the infant rat and that the addition of soybean oil emulsion to the TPN regimen dramatically reduced the down-regulation of CYP mRNAs and prevented the development of hepatic dysfunction. ${ }^{30)}$ When infant rats received an overdose of fat-free TPN for $4 \mathrm{~d}$, all of these mRNA levels were markedly decreased (Fig. 6). However, such down-regulation of CYP gene expression was prevented by the addition of a fat emulsion to the TPN regimen (Fig. 6).

It has been reported that induction of hepatic CYP2B1 and $2 \mathrm{~B} 2$ occurred in rats fed a $20 \%$ corn oil diet compared with rats fed a fat-free diet, whereas no induction of CYP2E1 was observed. ${ }^{31,32)}$ Among the members of the CYP2 family, CYP2B is likely to be more sensitive to fat ingestion. With regard to the CYP2C isoforms, the ethylmorphine demethy- 
lase activity (CYP2C11 and CYP2C2) and the benzphetamine dealkylase activity (CYP2C11) in rats that received TPN without fat were found to be decreased by $41 \%$ and $73 \%$, respectively, compared with rats that received the same hyperalimentation solution enterally. ${ }^{27)}$ The erythromycin demethylase activity (CYP3A2) in rat liver was also markedly decreased by the administration of TPN without fat. ${ }^{27)}$ Our results (Fig. 6) support these earlier observations. These findings indicate the great importance of including fat in the hyperalimentation regimen in order to maintain hepatic drug oxidation capabilities in animals.

\section{REGULATION OF FATTY ACID METABOLISM VIA CYP4A AND HORMONE RECEPTOR SUPERFAMILY IN FAT-CONTAINING TPN}

The CYP4As are fatty acid and prostaglandin hydroxylases that are abundantly expressed in the liver and kidney. ${ }^{24,33)}$ These enzymes can hydroxylate saturated and unsaturated fatty acids at the $\omega$ and $\omega-1$ positions, with a clear preference for the $\omega$ position. ${ }^{34)}$ The peroxisome proliferators-activated receptor- $\alpha(\operatorname{PPAR} \alpha)$ is a member of the nuclear hormone receptor superfamily, which requires another dimerization partner, the retinoid $\mathrm{X}$ receptor $(\mathrm{RXR} \alpha)$, for gene activation. $^{35)}$ It has been suggested that $\operatorname{PPAR} \alpha$ and $\operatorname{RXR} \alpha$ play important roles in hepatic CYP4A1 regulation. ${ }^{36)}$ We have observed that the infusion of excessive glucose results in the down-regulation of hepatic cytochrome P450 mRNA and that including fat in the TPN regimen is very important in preventing this effect (Fig. 6). ${ }^{30)}$ However, no reports describing in detail the relationships between the changes in CYP4A1 and nuclear receptors such as $\operatorname{PPAR} \alpha$ and $\operatorname{RXR} \alpha$ during TPN treatment have appeared in the literature.

Recently, we have demonstrated for the first time that the changes in PPAR $\alpha$ mRNA levels associated with overdose of fat-free or fat-containing TPN in infant rats may be one factor involved in regulating the level of CYP4A1 mRNA expression because the levels of CYP4A1 and PPAR $\alpha$ mRNA were strongly correlated. ${ }^{37)}$ Since the levels of CYP4A1 and $\operatorname{PXR} \alpha$ mRNA were weakly correlated, PXA $\alpha$ probably plays only a minor role in the regulation of CYP4A1 expression. Our results indicating the great importance of including fat in the TPN regimen in order to prevent CYP4A1 mRNA down-regulation may be related to the changes in PPAR $\alpha$ mRNA levels in the liver of the infant rat. It is also known that fatty acids are ligands for PPAR $\alpha$, providing strong evidence that they are endogenous $\operatorname{PPAR} \alpha$ activators. ${ }^{38,39)}$ Therefore, when a fat-free TPN regimen is used, it is likely that activation of PPAR $\alpha$ may not occur, and concomitantly, the expression of CYP4A1 mRNA may be down-regulated and the subsequent disturbances in fatty acid metabolism may lead to steatosis. The prevention of CYP4A1 mRNA down-regulation by the use of a fatty acid-containing TPN solution may be due to the activation of $\operatorname{PPAR} \alpha$. However, further study is needed to elucidate the precise mechanism by which the down-regulation of hepatic CYP4A1 mRNA expression following fat-free TPN is associated with changes in PPAR $\alpha$ mRNA expression.
SOYBEAN OIL IN TPN REGIMEN PREVENTS HEPATIC TRANSPORTER mRNA UP- OR DOWN-REGULATION

The ATP-binding cassette (ABC) transporter superfamily is one of the largest gene families of transmembrane proteins. The genetic variation in $\mathrm{ABC}$ transporter genes is a cause or contributor to a wide variety of drug-resistance phenotypes of cancers and metabolic diseases. ${ }^{40)}$ The organic ion transporters, which have been named SLC22, ${ }^{41)}$ belong to a superfamily of solute transporters. ${ }^{42)}$ Several ABC transporters are involved in bile acid formation in the liver and in hepatic clearance. ${ }^{43)} \mathrm{ABC}$ transporters such as MRP1 act as a drug-efflux pump, rendering cancer cells resistant to cytostatic drugs. ${ }^{44)}$ It has also been found that many xenobiotic transporters are regulated by various nuclear receptors. ${ }^{45,46)}$ Regarding the relationship between TPN and transporters, Tazuke et $a{ }^{47)}$ reported that multiple drug resistance protein (Mdr) 1 mRNA is increased following TPN administration.

In this review, we therefore describe our observations on the changes in the mRNA expression of hepatic xenobiotic transporters in the infant rat model following the administration of TPN with or without soybean oil emulsion. Overall, the results showed that the administration of TPN without fat resulted in a decrease or increase in many transporters involved in the transport of a variety of xenobiotics and endobiotics from the blood to hepatocytes and from hepatocytes to the bile. ${ }^{48)}$ Following the administration of TPN without fat, in particular, hepatocyte uptake transporters such as organic cation transporter (Oct) 1 and Oat2, biliary efflux transporters such as Mdr2 (also called MDR3 in humans), the bile salt export pump (Bsep), and Mrp2 were all decreased, whereas xenobiotic transporters such as Mdr1b, Mrp1, and Mrp5 were increased (Table 1). ${ }^{48)}$ However, the changes in these mRNA expression levels in the fat-containing TPN group were smaller than those in the fat-free TPN group or almost the same as those in the oral diet group.

Vos et $a l^{49)}$ reported that Mdr1b mRNA and Mrp1 mRNA were increased but Bsep/Spgp mRNA and Mrp2 mRNA were decreased by lipopolysaccharide treatment, and they suggested that endotoxin-induced cholestasis is induced by decreased Bsep and Mrp2 levels and that the up-regulation of Mdr1b and Mrp1 may confer resistance to hepatocytes against cytokine-induced metabolic stress. Recently, we also reported that Mdr1b mRNA and Mrp1 mRNA were in-

Table 1. Changes in Expression Levels of Hepatic Transporters after Administration of Fat-Free TPN

\begin{tabular}{lll}
\hline \hline Name & Abbreviation & $\begin{array}{c}\text { mRNA } \\
\text { expression }(\%)^{a}\end{array}$ \\
\hline $\begin{array}{l}\text { Hepatic uptake transporters } \\
\text { Organic cation transporter 1 }\end{array}$ & Oct1 & $\downarrow(40)$ \\
Organic anion transporter 2 & Oat2 & $\downarrow(33)$ \\
Biliary efflux transporters & & Mdr2 \\
Multiple drug resistance protein 2 & Bsep & $\downarrow(37)$ \\
Bile salt export pump & Mrp2 & $\downarrow(43)$ \\
Multidrug resistance protein 2 & Mrp6 & $\downarrow(27)$ \\
Multidrug resistance protein 6 & & $\uparrow(1580)$ \\
Xenobiotic transporters & Mdr1b & $\uparrow(144)$ \\
Multiple drug resistance protein 1b & Mrp1 & $\uparrow(201)$ \\
Multidrug resistance protein 1 & Mrp5 & \\
Multidrug resistance protein 5 & & \\
\hline
\end{tabular}

${ }^{a)}$ Values in parentheses indicate percentages relative to the oral diet group. 
creased but Bsep mRNA and Mrp2 mRNA were decreased in the infant rat model of hepatic dysfunction and steatosis induced by overdose of fat-free TPN. ${ }^{48)}$ Furthermore, it has been reported that the excessive administration of non-protein calories in TPN contributes to the development of cholestasis. $^{50,51)}$ Therefore, it appears that fat-free TPN-induced hepatic dysfunction, steatosis, and cholestasis, as well as endotoxin-induced cholestasis, may be caused by decreased Bsep and Mrp2 levels and that the up-regulation of Mdr1b and Mrp1 may confer resistance to hepatocytes against hyperalimentation-mediated metabolic stress due to the excessive administration of non-protein calories in TPN.

Mrp1 is located in the basolateral membrane, but its constitutive expression level in the liver is low under normal conditions, whereas Mrp2 is highly expressed in the canalicular membrane of hepatocytes. ${ }^{43}$ Bilirubin is rapidly and selectively taken up by the liver, biotransformed upon conjugation with glucuronate by UDP-glucuronosyltransferase 1A1 (UGT1A1), ${ }^{52)}$ and secreted into the serum across the basolateral membrane by $\mathrm{Mrp}^{43)}$ and into the bile across the canalicular membrane by Mrp2. ${ }^{432)}$ It has also been reported that human organic anion transporting polypeptide (OATP2) mediates the high-affinity transport of bilirubin. ${ }^{52)}$ Furthermore, Cekic et al. ${ }^{53)}$ reported that Mrp1 is up-regulated when the unconjugated bilirubin load is increased. In our study, the serum total and direct bilirubin concentrations in the fat-free TPN group were markedly higher than those in the other groups (i.e., the oral diet and fat-containing TPN groups). ${ }^{48)}$ We also observed a marked increase and a marked decrease in the expression levels of Mrp1 and Mrp2 mRNA, respectively, following the administration of fat-free TPN. ${ }^{48)}$ Therefore, it is possible that the increase in the serum bilirubin concentration observed in the fat-free TPN group might have been influenced by alterations in Mrp1 and/or Mrp2 following the excessive administration of fat-free TPN, reflecting the development of cholestasis.

Based on the findings of this animal study, it is suggested that changes in the expression of these transporters may affect the efficacy of pharmacotherapy such as the administration of anticancer agents, possibly resulting in severe adverse drug reactions or chemoresistance in pediatric patients receiving long-term TPN. The addition of a fat emulsion to the TPN regimen may maintain normal cell membrane transport function for a wide range of endogenous and exogenous compounds and reduce such adverse reactions dramatically.

SOYBEAN OIL IN TPN REGIMEN MAINTAINS mRNA LEVELS OF HEPATIC ANTIOXIDANT ENZYMES AND ALBUMIN

In the pathogenesis of non-alcoholic steatohepatitis such as that induced by fat-free TPN, oxidative stress/lipid peroxidation and its end products are thought to play a significant role. ${ }^{54)}$ Reactive oxygen species (ROS) may induce a stress response in the cells by altering the expression of antioxidant defense systems to rescue the cell. A comprehensive defense system against ROS is known to comprise the well-established superoxide dismutase (SOD)/catalase enzymatic system. $^{55)}$ The activity levels of $\mathrm{Cu}, \mathrm{Zn}$-superoxide dismutase $(\mathrm{CuZn}-\mathrm{SOD})$ and catalase are higher in the liver than in other tissues. ${ }^{56)} \mathrm{CuZn-SOD}$ dismutates two molecules of the super- oxide anion to oxygen and hydrogen peroxide, and the hydrogen peroxide is subsequently reduced to water by catalase. It is interesting to consider the expression of antioxidant defense systems in the liver with steatosis/cholestasis induced by overdose of fat-free TPN. Additionally, in order to maintain the cellular thiol-disulfide redox status under reducing conditions, living cells possess the GSH/glutaredoxin (Grx) system. ${ }^{57,58)}$

We have recently reported that the mRNA down-regulation of antioxidant enzymes such as CuZn-SOD, catalase, and Grx 1 was observed in the livers of infant rats that received an overdose of fat-free TPN. ${ }^{59)}$ Such defects in the antioxidant defense systems may result in the production of ROS, in the promotion of oxidative stress in the hepatocyte membrane, and thus in functional damage to the liver and elevated serum bilirubin concentrations.

We have also observed growth delay and hepatomegaly in rats that received fat-free TPN as compared with rats that were fed an oral diet. The liver is the main source of serum albumin. In protein-energy malnutrition, not only the serum albumin level but also the hepatic albumin mRNA level is known to be markedly decreased. ${ }^{55)}$ We therefore measured the level of hepatic mRNA expression of albumin. The results showed that expression in the fat-free TPN group was decreased to $30-40 \%$ that in the fat-containing TPN and oral diet groups, ${ }^{59)}$ indicating that the expression of albumin mRNA was maintained by the inclusion of fat in the TPN regimen.

Since the risk of developing TPN-related hepatic dysfunction is greater in young infants than in adults, hepatoprotective management during TPN is necessary to promote normal growth in infants. However, the long-term administration of TPN with carbohydrates as the sole source of calories may induce hepatic dysfunction and a reduction in serum albumin, which can be fatal to neonates or infants who do not receive oral feeding for a prolonged period. The use of an appropriate TPN formulation including a fat emulsion is of great importance in avoiding hepatic dysfunction and growth delay in pediatric patients.

\section{CLINICAL IMPLICATIONS OF SOYBEAN OIL-CON- TAINING TPN}

Our studies using the rat TPN model have shown that the hepatic dysfunction with steatosis and bilirubinemia observed in infant rats that received an overdose of fat-free TPN was associated with the mRNA down-regulation of enzymes responsible for gluconeogenesis and lipolysis and the up-regulation of lipogenesis. Such hepatobiliary dysfunction induced by fat-free TPN was associated with marked and selective down-regulation of hepatic mRNA levels of CYPs such as the CYP1, CYP2, and CYP3 families, suggesting a decrease in the CYP-mediated oxidative metabolism of therapeutic drugs. The addition of soybean oil emulsion to the TPN regimen dramatically reduced the down-regulation of these CYP mRNAs. The human CYP3A isoform, which is a major isoform in the perinatal period and infancy, ${ }^{29)}$ appears to play critical roles in drug metabolism and/or drug interaction in pharmacotherapy in pediatric patients. Drugs such as prednisolone and cyclosporin $\mathrm{A}$, which are metabolized by CYP3A4 in humans, ${ }^{60,61)}$ are commonly prescribed to pedi- 
atric patients with inflammatory bowel disease or Crohn's disease. The results of our study indicate that if such patients require parenteral hyperalimentation, the use of fat-free TPN may induce lethal adverse drug reactions due to impaired drug metabolism resulting from the decreased expression of CYP3A4. The inclusion of fat in the TPN regimen appears to be clinically essential for preventing such adverse drug reactions.

In addition, alterations in the mRNA expression of various hepatic xenobiotic transporters were also observed when fatfree TPN was administered to infant rats. Among the ABC transporters, the prognostic significance of MDR1/P-glycoprotein as an indicator of failure of chemotherapy and a poor outcome has been demonstrated in a number of clinical studies. $^{62,63)}$ MRP1 transports anticancer drugs such as etoposide, doxorubicin, and vincristine ${ }^{64-66)}$ and acts as a drug-efflux pump, rendering cancer cells resistant to cytostatic drugs. ${ }^{44)}$ We observed a marked increase in the expression levels of Mdr1b and Mrp1 mRNA following the administration of fatfree TPN, whereas no increase was noted following the administration of fat-containing TPN. ${ }^{48)} \mathrm{Mrp} 5$ is related to the transport of nucleotide analogs such as anti-HIV drugs. ${ }^{67)} \mathrm{We}$ also observed a marked increase in the expression levels of Mrp5 mRNA following the administration of fat-free TPN, whereas no increase in the expression levels of Mrp5 mRNA as well as Mdr1b or Mrp1 mRNA was noted following the administration of fat-containing TPN. ${ }^{48}$ ) Therefore, a TPN regimen containing fat can be recommended as a useful form of nutritional therapy in patients undergoing postoperative cancer chemotherapy or patients receiving anti-HIV drugs.

Furthermore, the reduction in albumin synthesis and the defects in the antioxidant defense systems observed in the fat-free TPN group may result in the production of ROS, the promotion of oxidative stress, functional damage to the infant liver, and consequently, growth delay or death. The addition of soybean oil to the TPN regimen was found to have a dramatic effect in preventing such adverse reactions in infant rats that received TPN without fat. Therefore, the use of an appropriate TPN formulation including a fat emulsion is of fundamental clinical importance in order to avoid hepatic oxidative dysfunction and growth delay in pediatric patients.

\section{CONCLUSION}

The pathogenesis of the hepatic dysfunction such as cholestasis and steatosis induced by TPN without fat is thought to be multifactorial and due to a complex mechanism involving changes in many targets such as enzymes related to the metabolism of sugar and fat, antioxidant enzymes, CYPs, transporters, and nuclear receptors.

Including fat (soybean oil fat emulsion) in the TPN regimen is of great clinical importance in preventing hepatic dysfunction and cholestasis, avoiding severe adverse drug reactions, and improving the safety of drug therapy, especially in neonates and infants.

\section{REFERENCES}

1) Peden V. H., Witzleben C. L., Skelton M. A., J. Pediatr., 78, 180-181 (1971).

2) Bernstein J., Chang C. H., Brough A. J., Heidelberger K. P., J. Pediatr. 90, 361-367 (1977).
3) Benjamin D. R., Am. J. Clin. Pathol., 76, 276-283 (1981).

4) Saitoh Y., Oyanagi H., Nippon Rinsho, 59 (Suppl. 5), 906-909 (2001) (in Japanese).

5) Oshita M., Takehara H., Yamaguchi M., Doi K., Ueda N., Naito S., Hiraoka I., Tashiro S., Clin. Nutr., 23, 1060-1068 (2004).

6) Dudrick S. J., Wilmore D. W., Vars H. M., Rhoads J. E., Surgery, 64 $134-142$ (1968).

7) Tashiro T., Meng H. C., J. Jpn. Surg. Soc., 17, 667-673 (1981) (in Japanese)

8) Yamaguchi M., Doi K., Nishimura M., Doi M., Kishimoto S., Koshitani O., Ichikawa S., Shinohara S., Ueda N., Naito S., Hiraoka I., Oshita M., Takehara H., J. JSPEN, 19, 71-79 (2004) (in Japanese).

9) Dahms B. B., Halpin T. C., Jr., Gastroenterology, 81, 136-144 (1981).

10) Hodes J. E., Grosfeld J. L., Weber T. R., Schreiner R. L., Fitzgerald J. F., Mirkin L. D., J. Pediatr. Surg., 17, 463-468 (1982).

11) Hughes C. A., Talbot I. C., Ducker D. A., Harran M. J., Gut, 24, 241248 (1983).

12) Hata S., Kamata S., Nezu R., Takagi Y., Okada A., JPEN J. Parenter Enteral Nutr., 13, 265-271 (1989).

13) Maini B., Blackburn G. L., Bistrian B. R., Flatt J. P., Page J. G., Bothe A., Benotti P., Rienhoff H. Y., J. Surg. Res., 20, 515-525 (1976) (in Japanese).

14) Spagnulo M. I., Iorio R., Vegnente A., Gastroenterology, 111, 716719 (1996).

15) Kubota A., Okada A., Imura K., Kawahara H., Nezu R., Kamata S. Takagi Y., J. Pediatr. Surg., 25, 618-621 (1990)

16) Spurr S. G., Grylack L. J., Mehta N. R., J. Parent. Ent. Nutr., 13 633-636 (1989).

17) Pappo I., Bercovier H., Gallilly R., Gallilly R., Feigin E., Freund H. R. JPEN J. Parenter. Enteral Nutr., 19, 80-82 (1995).

18) Rintala R. J., Lindahl H., Pohjavuori M., J. Pediatr. Surg., 30, $827-$ 830 (1995).

19) Teitelbaum D. H., Han-Markey T., Drongowski R. A., Coran A. G., Bayar B., Geiger J. D., Uitvlugt N., Schork M. A., JPEN J. Parenter. Enteral Nutr., 21, 100-103 (1997).

20) Alverdy J. A., Aoys E., Weiss-Carrington P., Burke D. A., J. Surg. Res., 52, 34-38 (1992).

21) Li J., Langkamp-Henken B., Suzuki K., Stahlgren L. H., JPEN J. Parenter. Enteral Nutr., 18, 303-307 (1994).

22) Li J., Kudsk K. A., Janu P., Renegar K. B., Surgery, 121, 542-549 (1997).

23) Kudsk K. A., Wu Y., Fukatsu K., Zarzaur B. L., Johnson C. D., Wang R., Hanna M. K., JPEN J. Parenter. Enteral Nutr., 24, 270-275 (2000).

24) Nishimura M., Yaguti H., Yoshitsugu H., Naito S., Satoh, T., Yakugaku Zasshi, 123, 369-375 (2003).

25) Rendic S., Drug Metab. Rev., 34, 83- 448 (2002).

26) Gonzalez F. J., Trends Pharmacol. Sci., 13, 346-352 (1992).

27) Knodell R. G., Steele N. M., Cerra F. B., Gross J. B., Solomon T. E., J. Pharmacol. Exp. Ther, 229, 589-597 (1984).

28) Tanaka E., J. Clin. Pharm. Ther, 23, 224-255 (1998).

29) Tateishi T., Nakura H., Asoh M., Watanabe M., Tanaka M., Kumai T., Takashima S., Imaoka S., Funae Y., Yabusaki Y., Kamataki, T. Kobayashi S., Life Sci., 61, 2567-2574 (1997).

30) Yamaguchi M., Yamauchi A., Nishimura M., Ueda N., Naito S., Biol. Pharm. Bull., 28, 143-147 (2005).

31) Kim H. J., Choi E. S., Wade A. E., Biochem. Pharmacol., 39, 14231430 (1990).

32) Yang C. S., Yoo J. S. H., Pharmacol. Ther, 38, 53-72 (1988).

33) Simpson A. E., Gen. Pharmacol., 28, 351-359 (1997).

34) Aoyama T., Hardwick J. P., Imaoka S., Funae Y., Gelboin H. V., Gonzalez F. J., J. Lipid Res., 31, 1477-1482 (1990).

35) Issemann I., Prince R. A., Tugwood J. D., Green S., J. Mol. Endocrinol., 11, 37-47 (1993).

36) Johnson E. F., Hsu M. H., Savas U., Griffin K. J., Toxicology, 181-182, $203-206$ (2002).

37) Nishimura M., Yamauchi A., Yamaguchi M., Ueda N., Naito S., Biol. Pharm. Bull., 28, 1517-1520 (2005).

38) Kliewer S. A., Sundseth S. S., Jones S. A., Brown P. J., Wisely G. B., Koble C. S., Devchand P., Wahli W., Willson T. M., Lenhard J. M. Lehmann J. M., Proc. Natl. Acad. Sci. U.S.A., 94, 4318-4323 (1997).

39) Forman B. M., Chen J., Evans R. M., Proc. Natl. Acad. Sci. U.S.A., 94, 4312-4317 (1997). 
40) Gottesman M. M., Ambudkar S. V., J. Bioenerg. Biomembr., 33, 453458 (2001)

41) Koehler M. R., Wissinger B., Gorboulev V., Koepsell H., Schmid M., Cytogenet. Cell Genet., 79, 198-200 (1997).

42) Marger M. D., Saier M. H., Jr., Trends Biochem. Sci., 18, 13-20 (1993).

43) Lecureur V., Courtois A., Payen L., Verhnet L., Guillouzo A., Fardel O., Toxicology, 153, 203-219 (2000).

44) Zaman G. J., Flens M. J., van Leusden M. R., de Haas M., Mulder H. S., Lankelma J., Pinedo H. M., Scheper R. J., Baas F., Broxterman H. J., Borst P., Proc. Natl. Acad. Sci. U.S.A., 91, 8822-8826 (1994).

45) Synold T. W., Dussault I., Forman B. M., Nature Med., 7, 584-590 (2001).

46) Kast H. R., Goodwin B., Tarr P. T., Jones S. A., Anisfeld A. M., Stoltz C. M., Tontonoz P., Kliewer S., Willson T. M., Edwards P. A., J. Biol. Chem., 277, 2908-2915 (2002).

47) Tazuke Y., Kiristioglu I., Heidelberger K. P., Eisenbraun M. D., Teitelbaum D. H., J. Parenter. Enteral Nutr., 28, 1 -6 (2004).

48) Nishimura M., Yamaguchi M., Yamauchi A., Ueda N., Naito S., Drug Metab. Pharmacokinet., 20, 46-54 (2005).

49) Vos T. A., Hooiveld G. J., Koning H., Childs S., Meijer D. K., Moshage H., Jansen P. L., Muller M., Hepatology, 28, 1637-1644 (1998).

50) Hata S., Jap. J. Surg. Metab. Nutr., 22, 157-169 (1988) (in Japanese).

51) Yamanouchi T., Suita S., Masumoto K., Nutrition, 14, 443-447 (1998).

52) Cui Y., Konig J., Leier I., Buchholz U., Keppler D., J. Biol. Chem., 276, 9626-9630 (2001).

53) Cekic D., Bellarosa C., Garcia-Mediavilla M. V., Rigato I., Pascolo L., Ostrow J. D., Tiribelli C., Biochem. Biophys. Res. Commun., 311,
$891-896$ (2003).

54) Spolarics Z., Meyenhofer M., Biochim. Biophys. Acta, 1487, 190200 (2000).

55) Sakuma K., Ohyama T., Sogawa K., Fujii-Kuriyama Y., Matsumura Y., J. Nutr., 117, 1141-1148 (1987).

56) Wohaieb S. A., Godin D. V., Diabetes, 36, 169-173 (1987).

57) Luikenhuis S., Perrone G., Dawes I. W., Grant C. M., Mol. Biol. Cell, 9, 1081-1091 (1998).

58) Rodriguez-Manzaneque M. T., Ros J., Cabiscol E., Sorribas A., Herrero E., Mol. Cell. Biol., 19, 8180-8190 (1999).

59) Nishimura M., Yamauchi A., Yamaguchi M., Ueda N., Naito S., Biol. Pharm. Bull., 28, 1265-1269 (2005).

60) Waxman D. J., Attisano C., Guengerich F. P., Lapenson D. P., Arch. Biochem. Biophys., 263, 424-436 (1988).

61) Kronbach T., Fischer V., Meyer A., Clin. Phamacol. Ther, 43, 630 635 (1988).

62) Chan H. S., Haddad G., Thorner P. S., DeBoer G., Lin Y. P., Ondrusek N., Yeger H., Ling V., New Engl. J. Med., 325, 1608-1614 (1991).

63) Verrelle P., Meissonnier F., Fonck Y., Feillel V., Dionet C., Kwiatkowski F., Plagne R., Chassagne J., J. Natl. Cancer Inst., 83, $111-116$ (1991).

64) Jedlitschky G., Leier I., Buchholz U., Barnouin K., Kurz G., Keppler D., Cancer Res., 56, 988-994 (1996).

65) Loe D. W., Deeley R. G., Cole S. P., Cancer Res., 58, 5130 - 5136 (1998).

66) Priebe W., Krawczyk M., Kuo M. T., Yamane Y., Savaraj N., Ishikawa T., Biochem. Biophys. Res. Commun., 247, 859-863 (1998).

67) Wijnholds J., Mol C. A., van Deemter L., de Haas M., Scheffer G. L., Baas F., Beijnen J. H., Scheper R. J., Hatse S., de Clercq E., Balzarini J., Borst P., Proc. Natl. Acad. Sci. U.S.A., 97, 7476-7481 (2000). 